\title{
Proton radiotherapy should be further developed in Poland
}

\author{
Adam Maciejczyk ${ }^{1}$, Aleksandra Sztuder ${ }^{2}$
}

Proton radiation therapy needs to be further developed in Poland by virtue of both epidemiological considerations and because this type of radiation exhibits very advantageous biological and physical properties. The underlying benefit of such therapy is to make lower integral radiation dose delivered to structures beyond a given target area, including critical organs, resulting in reduced toxicities for patients. Of somewhat less import is the improvement in dose distributions for target areas (vs photons), which can potentially bring about a better local control. As a result, proton radiotherapy is mainly indicated for paediatric cases, where any development of complications is most likely because of the long lifetimes and the heightened radiosensitivity of healthy tissues. The most recent studies also show that certain subpopulations of patients can benefit from proton beam radiotherapy in cases of widespread cancers such as from the lung or breast. A further advantage is found after conducting a cost-effectiveness analysis whereby proton beam radiotherapy was demonstrated as a cost-effective procedure, with both lowered costs for treating complications and indirect costs. By the term 'development' as used herein, it is understood that there is a need to open another proton therapy centre in Poland; this question however being left open in the presented article. Nevertheless, before taking such a high-level decision, the following requires consideration: the working experience garnered by the existing Cyclotron Centre at Bronowice (CCB), outcomes from current prospective clinical trials and, above all, delivering appropriately managed and coordinated oncological care for cancer patients in Poland regarding multi-centre collaboration between specialists.

NOWOTWORY J Oncol 2017; 67, 1:65-70

Key words: proton radiotherapy, indications, biological properties, physical properties, cost- effectiveness

Over many years, proton beam radiotherapy has been used as an alternative to photon radiation therapy. In global terms, centres for proton radiotherapy are undergoing dynamic development [1]. Regarding Poland, this technique was first used in Cracow in 2011 for treating patients suffering from ocular melanoma, where an ischronic cyclotron (AIC-144) was used with accelerated protons of up to $60 \mathrm{MeV}$ energy; this work being a collaboration between the Ophthalmology and Oncology Clinic of the University Hospital in Cracow, the M. Skłodowska-Curie Memorial Centre for Oncology Institute and the H. Niewodniczański Memorial Institute of Nuclear Physics at the Cracow branch of the Polish Academy of Sciences (PAN) [2]. For the latter, construction of a Cyclotron Centre at Bronowice (CCB) was started in March 2011, whereupon the Centre was ceremonially opened on the 15th October 2015; a Proteus-235 isochronous cyclotron having been installed, achieving a proton beam of 70-230 MeV [3].

On 27th May 2015, a report was published by the Proton Radiotherapy Team concerning the use of this technique for treating cancers outside the eyeball in Poland [4], where indications were based on analysing the latest literature that included proposals put forward by the aforesaid team from the Cracow branch of the M. SkłodowskaCurie Memorial Centre for Oncology Institute [4]. On June 15th 2016, legislation was passed by the Polish Minister for Health on the basis of Recommendation No. 85/2015 prepared by the Director of the Agency for Assessing Medi-

${ }^{1}$ Radiotherapy Department, Lower Silesian Oncology Center, Wrocław, Poland

${ }^{2}$ Teleradiotherapy Department, Lower Silesian Oncology Center, Wrocław, Poland 
cal Technologies and Tariffs made on 29th October 2015 for sanctioning refundable healthcare treatment regarding the use of 'Proton Radiotherapy for treating cancers outside the eyeball' as a guaranteed healthcare benefit in hospital treatment [5].

In June 2016, the Lesser Poland (Małopolska) Regional Branch of the NFZ (National Health Fund) announced a tender for tumour treatment by means of proton beams and from 30th September 2016, proton radiotherapy became available as a healthcare service in Poland delivered by the Centre for Oncology Institute in Cracow in agreement with the Bronowice Cyclotron Centre [3]. Indeed on the latter's website, it was officially reported that the first patient had undergone proton radiotherapy between 3rd November to 27th December 2016 [3] and was the result of a collaboration between the aforementioned institutes (i.e. the Cracow branch of the M. Skodowska-Curie Memorial Centre for Oncology Institute and the Cyclotron Centre at Bronowice IFJ PAN) [3]. An obvious question thus arises: should proton radiotherapy be further developed in Poland? Firstly however within this context, the word 'develop' requires clarification. Does it mean that training medical personnel is needed (including oncologists and medical physicists) along with conducting clinical trials using proton beams, and whether a second proton therapy centre should be established in Poland? It is the author's conviction that proton radiotherapy should undoubtedly be developed as is dictated by epidemiological circumstances and the exceptional biological and physical properties of this technique, which affords better protection to healthy organs as well supporting evidence from dosimetric studies and partly also from clinical trials. Furthermore, the cost-effectiveness of proton therapy is well recognised in the literature.

At present, increasing numbers of proton therapy centres have been observed worldwide; more than 90 such centres are estimated by 2020 [1]. This increase is linked to demand; one hadron therapy centre, (NB. protons being classified as hadrons), is recommended for a 8-10 million population [6]. Predictions have been made for the number of patients requiring this therapy per head of population where it is estimated that 20,000 patients per every 10 million will annually require photon radiotherapy, of whom 2,400 (about 12\%) should be of the proton kind [7]. The number of cancer patients in Poland is projected to increase from currently 310,000 to 350,000 by 2025 ; such cases constitute the second leading cause of mortality in Poland and the European Union [8]. These increases will in turn, thus further increase the number of patients requiring proton radiotherapy.

Undoubtedly the advantages of protons can ascribed to their biological properties: they possess a higher Relative Biological Effectiveness ratio (RBE) than photons, by 1.1 to 1.2 , as estimated by Pagnetti et al. [9]. This advan- tage is translated to the target irradiation area, but not to any critical organs. Intriguing reports have been published concerning a proposed advantage for using protons at the subcellular level within DNA and beyond DNA, together with at the cellular, microenvironmental and tissue levels [10]. At the subcellular level, qualitative and quantitative advantages of protons have been propounded for inducing double-stranded DNA breaks and clustered lesions (CL), (i.e. regions with many and varied breaks located on one or two opposite DNA strands), epigenetic changes (possible proton-induced hypermethylation) and a greater efficiency (by $50 \%$ ) for inducing reactive oxygen species (ROS) in clonogenic cells [10].

At the cellular level, proton beam irradiation may be more effective than photons for inducing apoptosis (by elevated mRNA expression of pro-apoptotic genes) and protons have potentially more varied effects (vs photons) on modulating the cell cycle [10]. Within tissue and the microenvironment levels, neoangiogenesis becomes inhibited i.e. reduction of pro-angiogenic proteins and pro-inflammatory factors, as well as migration and invasion becoming inhibited, (e.g. inter alia inhibition of metalloproteinases), [10]. In themselves however, protons possess unique physical characteristics that include: low entrance dose, enhanced by a'Spread Out Bragg Peak' (SOBP), a sudden rise followed by a sudden drop in dose (the so-called Bragg Peak), no exit dose and small amounts of lateral scattering [11]. The primary benefit of proton beam irradiation is therefore a smaller integral dose, (for structures outside target areas that include critical organs), which is associated with reduced toxicity, including that for secondary cancers.

Improvements in dose distribution in the target area is of lesser significance, as compared to photons, excepting potential improvements for local control (and consequently for instance, in overall survival). Because of such features, attempts are made for escalating the dose and for implementing hypofractionated schemes. In order that the unique characteristics of protons be demonstrated, the example of dosimetric analysis for paediatric patients can be used, which reveals that in most cancer cases, reduced doses are employed to critical organs (regarding moderate and near-maximum dose - D2\%) as well as smaller target volumes that are subjected to proton irradiation [12]. Indeed, proton therapy is a model example of the basic principle of radiological protection; ALARA (as low as reasonably achiev$a b l e)$, which requires that minimal doses of ionising radiation should be delivered when socio-economic factors are taken into consideration. It should be noted that in 2001, Dr Herman Suit presented the four basic tenets of proton radiotherapy:

- no advantage to any patient for any irradiation of any normal tissue exists. Normal tissues are defined here as tissues not suspected of involvement by tumor; 
- direct radiation complications never occur in unirradiated tissues;

- that a smaller treatment volume is superior is not a medical research question;

- one may only investigate the magnitude of the gain or the cost of achieving that gain [13].

Any therapeutic decisions should be taken on evidencebased medicine (EBM). Proton radiotherapy studies primarily consist of a large number of dosimetric analyses, modelling studies (based on radiobiological models with estimates of the Normal Tissue Complication Probability; NTCP) and clinical trials. It is noteworthy that Phase III randomised trials are necessary for proton radiotherapy to be more widely applied. This is reasonable, although developments in proton radiotherapy should not be halted, keeping in mind that only $10 \%$ of oncological recommendations are based on Level 1 evidence from clinical trials [14]. Some authors even consider that Phase III studies using proton and photon therapies are unethical [15], especially for paediatric patients; but surely a $0 \%$ dose is equivalent to $0 \%$ complications. Of course there is a need for follow-up which includes dosimetric analyses, modelling studies, clinical trials (also pragmatic clinical trials; PCTs) together with cost-effectiveness analyses. A highly interesting, but labour intensive idea is a web-based platform prototype that provides advice on choosing the radiation therapy (i.e. protons vs photons) for head and neck cancers that includes a comparison of histograms, possible toxicities and cost-effectiveness [16].

The best documented clinical trial when applying proton radiotherapy is on paediatric patients, (its use predominating in these cases), where smaller integral doses are employed which, given the potentially long survival time of convalescents and the likelihood of developing complications, become crucial to this age group. In cases of central nervous system (CNS) cancers in children, using proton radiotherapy is justified especially to those cases requiring irradiation of the cerebrospinal axis, pinealoblastoma, other primitive neuroectodermal tumours (PNETs; currently classified in 2016 according to the WHO as CNS cancers but not otherwise classified), anaplastic ependymoma (with documented dissemination into the cerebrospinal fluid) and choroid plexus carcinoma [17].

Using proton radiotherapy sounds appropriate and is confirmed by studies evaluating the effectiveness of this treatment and, above all else, its safety i.e. reducing the risk of adverse events $[17,18]$. The efficacy studies for proton beam radiotherapy on CNS cancers indicate high rates of overall survival [17]. Reducing the number of complications to healthy organs has been confirmed in numerous dosimetric and modelling studies showing decreased risks of: cardiac toxicity [19], premature radiotherapy-related ovarian failure [20], ototoxicity [21] or cognitive impairment [22]. Indeed, the first clinical data has now emerged on improved
Health-Related Quality of Life (HRQoL) in patients after receiving proton irradiation in childhood compared to photon therapy [23]. It appears there is unequivocal evidence supporting the use of proton therapy for low-grade gliomas in children in terms of dose distribution to critical organs and toxicity $[17,24]$. Indications on using proton radiotherapy for cases of highly differentiated gliomas should be established, given that they are the most commonly diagnosed brain tumours in children and thus constitute the most common cause for employing brain radiotherapy to this age group [17]. The value-added benefit of proton beam radiotherapy is also increased when cases of soft tissue sarcoma [25], chordoma and chondrosarcoma [26] and retinoblastoma [27] are diagnosed.

Out of the aforementioned diagnoses of childhood cancer, the Director of the Medical Technology Assessment and Tariff Assessment Agency recommends NFZ-funded proton radiotherapy for brain cancers, (that require irradiation of the cerebrospinal axis and selected highly differentiated gliomas that only include those cases where a significant benefit is expected of critical organ sparing compared to photon radiotherapy), as well as soft tissue sarcoma (located at the the base of the skull, paramaeningeal and paraspinal) [28]. A widely known radiobiological dictum applicable in paediatrics is the high intracellular radio-sensitivity regarding the CNS. The means for reducing doses to the CNS structures is thus provided when using proton radiotherapy which should be taken into account whenever extending the aforementioned indications becomes necessary, particularly for all cases of low- grade gliomas [17, 24], germ cell tumours [29] or ependymomas [30] or craniopharyngiomas [17], as well as for local recurrences requiring reirradiation within the CNS or head and neck regions.

An important benefit of using protons is also in reducing the risk of the so-called secondary tumours by over 2 or even 15 times according to dosimetric and modelling studies [31, 32]. However, based on the USA SEER data base (Surveillance, Epidemiology and End Results) regarding clinical studies, this risk is $5.2 \%$ when using proton radiotherapy but 7\% for photon therapy [33]; with the proviso that the observation period was relatively short.

Indications for therapy in adult patients are more limited, where although there are many dosimetric and modelling studies reported in the literature, there are fewer worthwhile clinical studies published. The recommendations of the Director of the Medical Technology Assessment and Tariff Assessment Agency concerning adult cancer include chordoma and chondrosarcoma of the base of the skull and paraspinal region, paranasal sinus tumors and low-grade gliomas [28]. Supporting scientific evidence, similar to childhood cancers, is equally applicable for favourable irradiation efficacy as likewise are the significantly reduced adverse reactions [34-38]. It seems justified in this case to consider 
extending the indications to include other head and neck tumours near the base of the skull, thereby enabling the neighbouring and radiosensitive structures of the CNS and vasculature to be protected [39].

The accrued benefit of proton beam treatment for tumours of the head and neck can also be used by patients being at high risk of oral mucosal complications. With the aid of proton beams, very satisfactory local responses were achieved with minimal toxicity; patients underwent radiochemotherapy up to a dose of $70 \mathrm{~Gy}$ at 2.12 per fraction, where the treatment response was $93.3 \%$ with minimal toxicity ( $0 \%$ of grade $\mathrm{G} 2$ mucositis) [40]. In cases of CNS cancers, low-grade gliomas, proton radiotherapy is publically refundable in instances where significant benefits can be predicted through critical organ sparing when compared to photon radiotherapy [28]. According to the literature data, indications for using proton irradiation should be considered in cases of atypical meningiomas, especially those located near critical organs [41]. It should be pointed out however, that recognised indications for proton irradiation in adults therefore include somewhat rare cancers. An obvious question seems to be whether proton beam radiotherapy can improve the therapeutic index for the most common tumours?

A study by Doyen et al. determined those diagnoses where dose reductions could be delivered to critical organs using proton beam irradiation; these being: non-small cell lung carcinomas, cancers of the breast (with nodal irradiation), oesophagus, pancreas, bile ducts, liver, prostate, rectum, anus, cervix, head and neck tumours (the preponderance of using protons is not necessarily repeated in each instance as comparing plans is required for each case), pleural mesothelioma, Hodgkin's lymphoma and retroperitoneal sarcomas [42]. It seems that there is a subpopulation of patients that can especially benefit from proton beam radiotherapy in cases of widespread cancers such as the lung, breast or oesophagus. In the former, the postulated benefit of using proton radiotherapy in lung cancer is that the dose can be escalated without increasing cardiopulmonary toxicity [43] along with a potential for extending patient survival by reducing pulmonary toxicity, oesophageal toxicity and lymphopenia.

At present, a randomised Phase III RTOG 1308 study is ongoing which compares patient overall survival after radiotherapy between proton and photon beam modes for cases of non-small cell lung cancer (Stages II to IIIB). Using proton radiotherapy for breast cancer may appear controversial, yet there are sufferers that may thereby gain benefit, of whom there are principally two such populations: patients vulnerable to cardiac complications (e.g. young women with cancer of the left breast without any chances of reducing the $5 \mathrm{~Gy}$ dose to the heart and who also suffer from existing cardiac disease or are undergoing combination therapy - anthracyclines and trastuzumab) and secondly, those patients vulnerable to secondary tumours (e.g. $<60$ years age and having a large irradiated volume), [44].

Another study, a Phase II NCT01758445 trial, is currently ongoing to investigate rates of adverse events following proton radiotherapy in patients suffering from stage II to III breast cancer requiring whole breast or thoracic cavity irradiation together with that of the locoregional lymphatic system as regards cardiac toxicity and secondary tumours 10 and 15 years after proton radiotherapy had been administered. In oesophageal cancer, a benefit is postulated for decreasing toxicity (cardiac, lung, kidneys and liver) where a dose escalation study (hyperfractionated proton therapy at doses 50.4 to $78 \mathrm{~Gy}$ ) showed no increased toxicities with the rate at 5 year follow-up being 84.4\% [45]. From 2012, patients are being recruited to a Phase II NCT 01512589 study which compares IMRT (Intensity Modulated Radiation Therapy) photon therapy with proton radiotherapy in oesophageal cancer in combination treatment with chemotherapy, taking into account safety and therapeutic efficiency.

Because of how the dose is deposited, proton radiotherapy may be a valuable, and indeed the only means of re-irradiation, particularly in cases of recurrence localised within the brain or head and neck regions [46, 47]. More long-term observations are however required, but above all else prospective studies are needed.

The concluding argument supporting the use of proton radiotherapy is cost-effectiveness. All radiotherapy requires expensive equipment and highly qualified staff, but in itself, it is not an expensive treatment and consumes only about $5 \%$ of a running oncology budget [2]. A Swiss study has found that the cost of proton radiotherapy is 2.4 times higher than IMRT [48].

It can be expected that over time, this can be reduced to 2.1 or even 1.7 times, however proton radiotherapy will probably always remain more expensive that photon therapy [48]. There are two vital economic measures used for analysing the efficiency of medical procedure outcomes: the cost of obtaining an extra 'Quality-Adjusted Life Year' (QALY) or an extra 'Life Year Gained' (LYG). As a general rule, if the cost of a given intervention is less than 44,665 EURO (i.e. $\$ 50,000$ ) for an extra LYG or QALY then a favourable price/quality ratio is achieved [1]. Nonetheless in Holland for example, societal acceptance for enabling an extra LYG comes to even 80,000 EURO. In Poland, the Health Cost Index obtained is compared with the so-called Profitability Threshold i.e. an outcome which calculates, at our country's GDP level, the maximum cost of a new treatment required for achieving a Unitary Health Effect, (in this case 1 LYG or 1 QALY), compared to those treatments in current use, which should not exceed the GDP per capita by 3 times [28]. In 2015, such threshold estimates were 119,577 PLN (i.e. $3 \times 39,859$ PLN), [28]. At the same time, when assum- 
ing average expenses, the cost of a single patient treated abroad ranges from 21,854 PLN to 581,894 PLN (mean of 140,202 PLN), whereas the estimated cost in Poland, according to the Health Problem Card data is 130,219.53 PLN [28]. It should be noted that in performing an economic analysis, all cost elements of any further treatment are included whenever treating photon radiotherapy toxicity is required, for example ototoxicity in cases of medulloblastoma [49], cardiotoxicity and the risk of secondary tumours as well as indirect costs such as: absenteeism from work, presenteeism (coming to work despite ill health; associated with both lowered productivity and work quality), premature death and being incapacitated together with absenteeism and presenteeism of the carers.

It should also be stressed that the lower the exposure of healthy tissue to irradiation achieved in proton radiotherapy may permit hypofractionation to be increasingly used, which represents a very cost-effective means of dose delivery and raised local tumour control resulting in decreased costs for reirradiation, salvage surgery and palliative chemotherapy. Furthermore, the operative life-span of proton radiotherapy equipment is 30 years and over, whereas it is shorter for photon accelerators [50]. According to the literature, proton beam radiotherapy offers cost-effective treatment in diagnosed cases of: medulloblastoma, selected patient groups with locally advanced lung cancer and certain high-risk cancers of the head and neck [1].

Concluding therefore, proton radiotherapy needs to be developed because of increased cancer rates (that translate into increased subpopulations of patients requiring proton beam radiotherapy) and the need to expand the list of diagnoses that are recommended to secure guaranteed benefits, (based on clinical study data and economic analyses). This diagnoses list should include the following: CNS tumours in children (mainly ependymomas, germ cell cancers and lowgrade gliomas), whilst for adults atypical meningiomas, head and neck cancers localised to the base of the skull as well as selected breast, lung and oesophageal cancers. Such developments should foremost be understood to mean an urgent need to create a skilled workforce inter alia doctors, whereby the process of qualifying patients for proton radiotherapy could take place at the level of regional health centres.

Is it thus appropriate to open another proton radiotherapy centre and is the epidemiological evidence sufficient to justify this? These questions we leave open.

Before replying to these questions I think one should first consider whether oncological treatment is sufficiently well organised in Poland to cope, particularly when it comes to collaboration between specialists from multi-centres and with coordinating healthcare for cancer patients. I personally believe that such patients deserve access to modern therapies, but in cases where high-cost therapies are needed, (like proton radiotherapy), then the whole process of treatment should be very well planned including taking into consideration close patient access to cancer units that are experienced in surgical treatment and systemic care for those patients that can most benefit. It should be remembered that the basis of cancer treatment is combined therapy and it is necessary to constantly strive for improving the functioning of the oncology treatment system in which, increasingly, proton radiotherapy is occupying a more justifiable/prominent position.

\section{Conflict of interest: none declared}

\section{Prof. Adam Maciejczyk, MD, PhD}

Lower Silesian Oncology Center

pl. Hirszfelda 12

53-413 Wrocław, Poland

e-mail:adam.maciejczyk@dco.com.pl

Received \& Accepted: 18 Jun 2017

Based on the presentation at the IV Annual Conference of the Nowotwory Journal of Oncology, 'Oncological Debates', held in Warszawa, 8-9th April 2016

\section{References}

1. Verma V, Mishra MV, Mehta MP. A systematic review of the cost and cost-effectiveness studies of proton radiotherapy. Cancer 2016; 122 : 1483-1501.

2. Sas-Korczyńska B, WalasekT, Romanowska-Dixon B. Radioterapia hadronowa w Krakowie - przeszłość, teraźniejszość i przyszłość. Nowotwory J Oncol 2014; 64: 251-257.

3. Centrum Cyklotronowe Bronowice < https://ccb.ifj.edu.pl/pl> [19.04.2017].

4. Dziadziuszko R et al. Wskazania do radioterapii protonowej nowotworów zlokalizowanych poza narzadem wzroku w Polsce. Raport Zespołu Konsultanta Krajowego do spraw Radioterapii Protonowej. Gdańsk, 27 maja 2015.

5. Internetowy System Aktów Prawnych — ISAP <http://isip.sejm.gov. pl/> [19.04.2017]. Dziennik Ustaw Rzeczypospolitej Polskiej, poz. 855, Warszawa, 15 czerwca 2016 r. Rozporządzenie Ministra Zdrowia z dnia 6 czerwca 2016 r. zmieniające rozporządzenie w sprawie świadczeń gwarantowanych z zakresu leczenia szpitalnego.

6. Lievens $Y$, Walter Van den Bogaert W. Proton beam therapy: too expensive to become true? Radiother Oncol 2005; 75: 131-133.

7. Nunes Marcos d'Ávila. Protontherapy versus carbon ion therapy: advantages, disadvantages and similarities. Cham et al.: Springer, 2015.

8. Innowacyjneterapie onkologiczne.Propozycja poprawypolskiego systemu opieki onkologicznej, 2015. Report funded by Platforma Farmaceutyczna Pracodawców RP.

9. Paganetti $\mathrm{H}$, Niemierko A, Ancukiewicz $\mathrm{M}$ et al. Relative biological effectiveness (RBE) values for proton beam therapy. Int $J$ Radiat Oncol Biol Phys 2002; 53: 407-421.

10. Girdhani S, Sachs R, Hlatky L. Biological effects of proton radiation: what we know and don't know. Radiat Res 2013; 179: 257-272.

11. Sas-Korczyńska B, Jakubowicz J. Radioterapia protonowa - dlaczego i kiedy? Medycyna Praktyczna. Onkologia 2013; 04: 63.

12. Kristensen I, Nilsson K, Nilsson P. Comparative proton and photon treatment planning in pediatric patients with various diagnoses. IJPT 2015; 2: 367-375.

13. Suit $\mathrm{H}$. The Gray Lecture 2001: coming technical advances in radiation oncology. Int J Radiat Oncol Biol Phys 2002; 53: 798-809.

14. Poonacha TK, Go RS. Level of scientific evidence underlying recommendations arising from the National Comprehensive Cancer Network clinical practice guidelines. J Clin Oncol 2011; 29: 186-191.

15. Sheehan $\mathrm{M}$, Timlin C, Peach $\mathrm{K}$ et al. Position statement on ethics, equipoise and research on charged particle radiation therapy. J Med Ethics 2014; 40: 572-575.

16. Cheng Q, Roelofs E, Ramaekers BL et al. Development and evaluation of an online three-level proton vs photon decision support prototype 
for head and neck cancer - comparison of dose, toxicity and cost-effectiveness. Radiother Oncol 2016; 118: 281-285.

17. Laprie $A, H u Y$, Alapetite $C$ et al. Paediatric brain tumours: A review of radiotherapy, state of the art and challenges for the future regarding protontherapy and carbontherapy. Cancer Radiother 2015; 19:775-789.

18. Yock TI, Yeap BY, Ebb D et al. A phase II trial of proton radiotherapy for medulloblastoma: Preliminary results; <http://ascopubs.org/doi/ abs/10.1200/jco> [19.04.2017].

19. Zhang R, Howell RM, Homann $\mathrm{K}$ et al. Predicted risks of radiogenic cardiac toxicity in two pediatric patients undergoing photon or proton radiotherapy. Radiat Oncol 2013; 8: 184.

20. Pérez-Andújar A, Newhauser WD, Taddei PJ et al. The predicted relative risk of premature ovarian failure for three radiotherapy modalities in a girl receiving craniospinal irradiation. Phys Med Biol 2013; 58: 3107-3123.

21. Moeller BJ, Chintagumpala M, Philip JJ et al. Low early ototoxicity rates for pediatric medulloblastoma patients treated with proton radiotherapy. Radiat Oncol 2011; 6: 58.

22. Merchant TE. Clinical controversies: proton therapy for pediatric tumors. Semin Radiat Oncol 2013; 23: 97-108.

23. Yock TI, Bhat S, Szymonifka J et al. Quality of life outcomes in proton and photon treated pediatric brain tumor survivors. Radiother Oncol 2014; 113: 89-94.

24. Hug EB, Muenter MW, Archambeau JO et al. Conformal proton radiation therapy for pediatric low-grade astrocytomas. Strahlenther Onkol 2002; 178: 10-17.

25. Ladra MM, Szymonifka JD, Mahajan A et al. Preliminary results of a phase II trial of proton radiotherapy for pediatric rhabdomyosarcoma. J Clin Oncol 2014; 32: 3762-3770.

26. Rombi B, Ares $C$, Hug EB et al. Spot-scanning proton radiation therapy for pediatric chordoma and chondrosarcoma: clinical outcome of 26 patients treated at Paul Scherrer Institute. Int J Radiat Oncol Biol Phys 2013; 86: 578-584.

27. Sethi RV, Shih HA, Yeap BY et al. Second nonocular tumors among survivors of retinoblastoma treated with contemporary photon and proton radiotherapy. Cancer 2014; 120: 126-133.

28. Agencja Oceny Technologii Medycznych i Taryfikacji. Rekomendacjanr 85/2015 z dnia 29 października 2015 r. Prezesa Agencji Oceny Technologii Medycznych i Taryfikacji w sprawie zakwalifikowania świadczenia opieki zdrowotnej „Radioterapia protonowa nowotworów zlokalizowanych poza narządem wzroku" jako świadczenia gwarantowanego z zakresu leczenia szpitalnego.

29. MacDonald SM, Trofimov A, Safai S et al. Proton radiotherapy for pediatric central nervous system germ cell tumors: early clinical outcomes. Int J Radiat Oncol Biol Phys 2011; 79: 121-129.

30. Macdonald SM, Sethi R, Lavally B et al. Proton radiotherapy for pediatric central nervous system ependymoma: clinical outcomes for 70 patients. Neuro Oncol 2013; 15: 1552-1559.

31. Miralbell R, Lomax A, Cella L et al. Potential reduction of the incidence of radiation-induced second cancers by using proton beams in the treatment of pediatric tumors. Int J Radiat Oncol Biol Phys 2002; 54: 824-9.

32. Dennis ER, Bussiere MR, Niemierko A et al. A comparison of critical structure dose and toxicity risks in patients with low grade gliomas treated with IMRT versus proton radiation therapy. Technol Cancer Res Treat 2013; 12: 1-9.
33. Chung CS, Yock TI, Nelson K et al. Incidence of second malignancies among patients treated with proton versus photon radiation. Int $\mathrm{J}$ Radiat Oncol Biol Phys 2013; 87: 46-52.

34. Pehlivan B, Ares C, Lomax AJ et al. Temporal lobe toxicity analysis after proton radiation therapy for skull base tumors. Int J Radiat Oncol Biol Phys 2012; 83: 1432-1440.

35. Deraniyagala RL, Yeung D, Mendenhall WM et al. Proton therapy for skull base chordomas: an outcome study from the University of Florida Proton Therapy Institute. J Neurol Surg B Skull Base 2014; 75: 53-57.

36. Zenda S, Kawashima M, Arahira S et al. Late toxicity of proton beam therapy for patients with the nasal cavity, para-nasal sinuses, or involving the skull base malignancy: importance of long-term follow-up. Int J Clin Oncol 2015; 20: 447-454.

37. Maquilan G, Grover S, Alonso-Basanta M et al. Acute toxicity profile of patients with low-grade gliomas and meningiomas receiving proton therapy. Am J Clin Oncol 2014; 37: 438-443.

38. Shih HA, Sherman JC, Nachtigall LB et al. Proton therapy for low-grade gliomas: Results from a prospective trial. Cancer 2015; 121: 1712-1719.

39. Morimoto K, Demizu Y, Hashimoto N et al. Particle radiotherapy using protons or carbon ions for unresectable locally advanced head and neck cancers with skull base invasion. Jpn J Clin Oncol 2014; 44: 428-434.

40. Frank SJ, Cox JD, Gillin M et al. Multifield optimization intensity modulated proton therapy for head and neck tumors: a translation to practice. Int J Radiat Oncol Biol Phys 2014; 89: 846-853.

41. Madani I, Lomax AJ, Albertini F et al. Dose-painting intensity-modulated proton therapy for intermediate- and high-risk meningioma. Radiat Oncol 2015; 10: 72-79.

42. Doyen J, Falk AT, Floquet $\mathrm{V}$ et al. Proton beams in cancer treatments: clinical outcomes and dosimetric comparisons with photon therapy. Cancer Treat Rev 2016; 43: 104-112.

43. Nguyen QN, Ly NB, Komaki R et al. Long-term outcomes after proton therapy, with concurrent chemotherapy, for stage II-III inoperable non-small cell lung cancer. Radiother Oncol 2015; 115: 367-372.

44. Eugen BH. Proton therapy for breast cancer. ESTRO course. Particle therapy. Kraków, 14-18.03.2016.

45. Mizumoto M, Sugahara S, Okumura T et al. Hyperfractionated concomitant boost proton beam therapy for esophageal carcinoma. Int $J$ Radiat Oncol Biol Phys 2011; 81: e601-606.

46. Romesser PB, Cahlon O, Scher ED. Proton beam reirradiation for recurrent head and neck cancer: multi-institutional report on feasibility and early outcomes. Int J Radiat Oncol Biol Phys 2016; 95: 386-395.

47. Mizumoto M, Okumura T, Ishikawa E. Reirradiation for recurrent malignant brain tumor with radiotherapy or proton beam therapy. Technical considerations based on experience at a single institution. Strahlenther Onkol 2013; 189: 656-663.

48. Hirano $\mathrm{E}$, Fuji $\mathrm{H}$, Onoe $\mathrm{T}$ et al. Cost-effectiveness analysis of cochlear dose reduction by proton beam therapy for medulloblastoma in childhood. J Radiat Res 2014; 55: 320-327.

49. Chuong MD, Mehta MP, Langen K et al. Is proton beam therapy better than standard radiation therapy? The available evidence points to benefits of proton beam therapy. Clin Adv Hematol Oncol 2014; 12: 861-864.

50. Mailhot Vega R, Kim J, Hollander A et al. Cost effectiveness of proton versus photon radiation therapy with respect to the risk of growth hormone deficiency in children. Cancer 2015; 121: 1694-1702. 